\title{
ХАЛЯЛЬНАЯ (АДАЛЬНАЯ) ПРОДУКЦИЯ: НОРМАТИВНОЕ РЕГУЛИРОВАНИЕ «РЕЛИГИОЗНОЙ» СЕРТИФИКАЦИИ НА ПОТРЕБИТЕЛЬСКОМ РЫНКЕ РОССИИ И КАЗАХСТАНА: НОВАЦИИ ЗАЩИТЫ ПРАВ ПОТРЕБИТЕЛЕЙ В 2014-2015 ГГ.
}

\begin{abstract}
Аннотация: Предметом настоящей статьи является сфера отношений, складывающаяся в рамках технико-правового регулирования продуктов «адал» (халал, халяль), получившая относительно недавно свое развитие в мировой рыночной инфраструктуре, и затронувшей, в частности, рынки Российской Федерации и Республики Казахстан. Авторами была поставлена цель мониторинга произошедиих в 2015 г. изменений 8 сфере маркировки продукции, а также составления прикладного алгоритма распознавания обозначенных халяльных товаров для заинтересованных потребителей, а также выявления проблем правового регулирования. В статье не только проведен анализ особенностей сертификации халяльной продукции (технико-правовое регулирование), но и рассмотрень отдельные случаи злоупотребления правом. В статье автором использовались методы анализа, абстрагирования и сравнительного правоведения, в результате применения которых определены условия эффективности правоприменения в каждом государстве. В ходе статьи были сделаны выводы и предложения по исследуемой тематике, необходимые для успешного функционирования халяльной индустрии в Российской Федерации и других странах СНГ. Реализация данных предложений поможет повысить не только эффективность механизма защиты прав потребителей данной продукции, а также позволит оказывать влияние на недобросовестных субъектов предпринимательской деятельности, поскольку последние будут вынуждены нести риск наравне с государством, подрывая, в случае нарушения ими общих норм и правил, авторитет религиозной продукции своей страны на международной арене.
\end{abstract}

Ключевые слова: Халал (халяль), адал, техническое регулирование, стандартизация, производитель, добровольная сертификация, продукиия, качество, безопасность, защчта прав потребителей.

Abstract: This article discusses the legal and technical regulations in the sphere of halal products. The trade in halal products has recently expanded in the global market, including the Russian Federation and the Republic of Kazakhstan. The authors have observed the changes in the product labelling in 2015 and elaborated some practical methods for consumers concerned with identifying the "halal" labeled products. They have also looked into issues that may arise in the legal regulation of this sphere. In addition to analyzing the specifics in the products certification (legal and technical regulation), the authors also identify some examples of rights abuses. Recommendations provided and conclusions reached on the subject in question can be essential for a successful trade performance of halal merchandise in the Russian Federation and other countries of the CIS. The implementation of the authors' proposals can contribute to both, a more effective protection of consumer rights, and have an impact on commercial performers acting in bad faith, as the latter would bear a risk on an equal basis with the state. In case of breaching common rules and regulations, such performers would discredit the religious products made in their countries on the global market.

Keywords: Products, voluntary certification, manufacturer, standardization, technical regulation, adal, halal, quality, safety, protection of consumer rights.

Статья выполнена в рамках НИР «Гражданско-правовое регулирование охраны и защиты прав граждан на жизнь и здоровье в РФ» (T. №1.4.15).

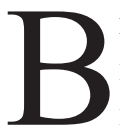
мировой рыночной инфраструктуре совсем недавно получила развитие относительно новая, но показавшая себя как довольно рентабельная индустрия т.н. «халяльной» (или как её ещё называют, «адальной») продукции, успевшей, в частности, затронуть рынки Российской Федерации и Республики Казахстан. Согласно мониторинговым данным, рынок продуктов питания «халал» на сегодняшний день оценивается в $\$ 700$ млрд. в год [10], причём первенство в производстве товаров (фармацевтических препаратов (к примеру, витаминов, в которых нет животных продуктов (желатина), запрещенных исламом [3]), косметики (такие крема не имеют спирта в своём составе, а губная помада производится без использования животных жиров), продуктов питания) и оказания услуг стандарта халал 
принадлежит в превалирующей своей массе исламским странам (национальное большинство которых составляют мусульманские потребители, чьи предпочтения основаны на канонах Шариата).

Следует отметить, что, в целом, халяльная пища по внешнему виду ничем не отличается от других продуктов питания, но её природа, равно как и специфичный процесс обработки и производства, и, в особенности, ингредиентный состав всегда отталкиваются от исламских законов [7]. Поэтому особую значимость в связи с этим приобретает добровольная сертификация подобной продукции и стандартизация её качества.

Необходимо отметить, что «Халяль» - индустрия на территории нашей страны начала своё развитие более 12 лет тому назад. Старт данному процессу дало принятие в 2002 г. Федерального закона от 27 декабря 2002 г. № 184-Ф3 «О техническом регулировании» (далее - Ф3 № 184) и введение в действие Свода международных стандартов $\mathrm{OOH}$ на продукты питания (Пищевой Кодекс), в составе которого числится два методических стандарта, в т.ч. в отношении использования маркировки «Halal» [11]. Оба этих акта стали основой для разработки и введения в действие первого как в истории России, так и всех стран СНГ, стандарта добровольной сертификации «Халяль» в 2003 г. Советом муфтиев России [1], который впоследствии был взят за основу в Республике Казахстан, в российских республиках Татарстан и Башкортостан.

На практике весомым аргументом в пользу предпочтения определенным кругом потребителей халяльных продуктов другим товарам служит нанесённый на упаковку логотип Совета муфтиев РФ, в силу того, что он, как правило, вызывает логичные ассоциации о заслуженном авторитете этой организации. По общему правилу, каждый производитель принимает добровольное решение о сертификации, когда заявляет о соответствии своих товаров или услуг халяльным требованиям. В противном случае, если он использует такую маркировку без подтверждения религиозным органом, то, по нашему мнению, нарушает законодательство, вводя тем самым в заблуждение потребителей. Как было нами отмечено ранее [6], в этом направлении существуют глубоко укоренившиеся проблемы. Так, не имея чётко очерченного контингента покупателей, не утвердив своих позиций и влияния среди конкурирующих предприятий, отдельные фирмы делают упор в развитии на иллюзорном следовании за известными международными институтами и брендами.
Тем не менее, производитель не всегда является стороной, стремящейся извлечь прибыль буквально из «ничего»: важна добросовестность органа добровольной религиозной сертификации. Частным случаем проявления такого злоупотребления можно назвать заявления о наличии прав на выдачу международного сертификата, дающего шанс на выход на мировой рынок без какого-либо аудита с импортирующей стороны, хотя де-факто это действие не более чем настоящая фикция [9]. Безусловно, предпринимателям, имеющим долгосрочные планы по экспорту на иностранные рынки, особенно мусульманских стран данной продукции, следует обращать внимание на эту информацию.

Переходя к анализу адальной сферы в Республике Казахстан, следует отметить, что, как и в целом по всему миру, так и применительно для Республики Казахстан большим спросом пользуется именно пищевая сфера халяльной индустрии: замечено, что сертификаты на производство халальной продукции имеют множество предприятий по всей стране. Что является довольно странным, ведь как таковых законодательных актов, устанавливающих и регулирующих процедуру выдачи сертификатов соответствия продукции со знаком «Халал», в Республике Казахстан до настоящего времени не было принято. Так, например, если завтра обратиться в суд, то он не сможет принять решение, халал это или не халал, потому что нормативов нет (этот вопрос обходит стороной и Закон Республики Казахстан от 09 ноября 2004 г. № 603- II «О техническом регулировании», и Закон Республики Казахстан от 04 мая 2010 г. № 274- IV «O защите потребителей»).

В 2014 г. произошел скандал по поводу деятельности ОЮЛ «Ассоциация халал индустрия Казахстана» (не религиозная, а предпринимательская негосударственная организация), которая осуществляла деятельность по определению качественных показателей халальных товаров с дальнейшей выдачей сертификатов. В сущности, это ОЮЛ никогда не сможет дать разрешение на канонический запрет или же, наоборот, запретить то, что, по сути, является разрешенным. Тогда, в ходе лабораторного исследования, Агентство по защите прав потребителей Республики Казахстан обнаружило в колбасных изделиях прошедших «сертификацию» производителей свиной шпик, запрещённую к употреблению Кораном [2], хотя отдельными журналистами подобные факты активно опровергались [4]. В настоящее время деятельность сайта данного ОЮЛ прекращена. 
Таким образом, с негласного «разрешения» законодателя в Казахстане формируется отрицательная тенденция, согласно которой вся ответственность ложится только на совесть и богобоязненность производителей. Потребителю остаётся только верить, что бизнес не наживается на их следовании канонам. Из вышеприведённого примера становится ясно, что если производитель намерен что-то скрыть - он скроет, равно и ритейлер не отбракует харамный товар.

Следует отметить, что интерес к такой продукции возрастает, а значит, появляется необходимость в обученных кадрах по сертификационной проверке той или иной фирмы в упомянутых отраслях. Об отрицательной тенденции свидетельствует и факт, что в России за всё время существования религиозной сертификации было выдано около 100 сертификатов по халал, в Казахстане же - 1000, притом, что рынок последнего намного меньше, а сертификатов оказалось в 10 раз больше [5].

Проблема отсутствия правовой регламентации активизирует деятельность различных общественных фондов, которые выступают на позициях того, чтобы право регулирования и оперирование термином «адал», как и выдача надлежащих сертификатов официально закрепилось за Духовным Управлением Мусульман Казахстана (далее - ДУМК) или муфтиятом. Однако возникает следующая проблема. Республика Казахстан считается светским государством, поэтому правительство не вправе затрагивать подобным образом религиозную сферу и, более того, ставить на государственный конвейер выпуск лицензий и сертификатов.

17 февраля 2015 г. представители ДУМК предложили упразднить маркировку «Халал» (арабск.) и вместо неё ввести маркировку «Адал» (казахск.), параллельно подготовив спецлабораторию из 250 квалифицированных имамов. Полученный ранее сертификат с этого года считается недействительным. Чтобы получить разрешение на использование соответствующей марки, производители обязаны, кроме всего прочего, установить камеры видеонаблюдения на своих предприятиях в целях того, чтобы покупатели могли в онлайн-режиме наблюдать за конвейером. В настоящее время сертификаты получили только 3 организации $[8,13,14]$. Правда, данная спецлаборатория будет заниматься только пищевой отраслью, не затрагивая сферу услуг и работ, что является некоторым упущением, притом, что задумка ДУМК приняла качественно новое русло в халяльном вопросе и, с нашей точки зрения, будет иметь позитивные долгосрочные результаты.
До тех пор же, пока частые случаи злоупотребления маркировкой «халал» будут продолжаться и соответствующие предприятия пройдут процедуру религиозной сертификации ДУМК-ом, потребителям стоит быть вдвойне более осторожными в выборе адальной продукции и её логотипов посредством тщательной проверки этикетки каждого товара.

Таким образом, по нашему мнению, для успешного функционирования халяльной индустрии в Российской Федерации, Республики Казахстан и других странах СНГ необходимо предпринять следующие действия. Во-первых, следует пересмотреть/образовать нормативно-техническую базу с учётом религиозной специфики, в особенности в тех странах СНГ, в которых большинство населения составляют мусульмане, т.к. у них и, в частности, у иудеев существуют одни из самых строгих запретов, для проведения единой правовой политики в области специфической продукции, работ и услуг; данные изменения ни в коем случае не должны умалять светский характер какого-либо государства.

Во-вторых, для объективной, независимой, всесторонней, достоверной сертификации халяльной продукции организациям формата ДУМК и Совета муфтиев России необходимо создать на уровне СНГ орган добровольной сертификации и испытательную лабораторию, которые стали бы координировать деятельность и устанавливать единые стандарты качества продукции соответствующих органов на региональном уровне, в т.ч. в рамках Таможенного союза. Причём тестирование в спецлаборатории должно осуществляться как на физико-химические, микробиологические показатели, ГМО и наличие запрещенных Кораном ингредиентов в продуктах питания, так и на соответствие различных работ и услуг установленным стандартам качества.

B-третьих, при появлении такой дифференциации следует выявить системные связи религиозной сертификации для отраслевой, территориальной, потребительской классификации, и, основываясь на ней, выразить общие правила и принципы (к примеру, прозрачности и гласности производственного процесса, свободной конкуренции и т.п.) религиозной индустрии бизнеса, оценить её рентабельность.

Таким образом, реализовав данный перечень, государство как пресечёт погоню производителей за легкими деньгами, так и их пренебрежительное отношение к правам потребителей, т.к. производители будут вынуждены нести риск наравне с государством, подрывая в случае нарушения ими общих правил авторитет религиозной продукции своей страны на международной арене. 


\section{Библиография:}

1. Ахметова Д. Россия - Организация Исламского Сотрудничества: новые перспективы сотрудничества в сфере «Халяль» индустрии [Электронный ресурс] / ОС Совета муфтиев России. Доступ к статье: www.muslim.ru/articles/114/1269/.

2. В Казахстане в продукции «Халал» обнаружена свинина [Электронный ресурс] / SunnaPress.com. Доступ к статье: http://sunnapress.com/news/newskazakhstan/8105-v-kazakhstane-v-produktsii-khalal-obnaruzhena-svinina.html.

3. Достижение халал-индустрии представят в Астане [Электронный ресурс] / Капитал.kz. Доступ к статье: http://kapital. kz/economic/2127/dostizhenie-halal-industrii-predstavyat-v-astane.html.

4. Канафина Ж. Скандал на рынке халал в Казахстане. Кто подложил свинью? [Электронный pecypc] / centrasia.ru. Доступ к статье: www.centrasia.ru/news2.php?st=1408137780; www.caravan.kz/article/90400.

5. Каримова Ж., Акимбекова А. Халал на свободе [Электронный ресурс] / VOX POPULI. Доступ к статье: www.voxpopuli. $\mathrm{kz} / \mathrm{main} / 2136-\mathrm{khalal}-\mathrm{na}$-svobode.html.

6. Кирикова А.А., Абакумова Е.В. Современные тенденции в сфере защиты прав потребителей: проблемы сертификации на российском потребительском рынке // Юридические исследования. - 2015. - № 2. - C.1-11. DOI: 10.7256/24097136.2015.2.14097. URL: http://e-notabene.ru/lr/article_14097.html.

7. Особенности Халяльного маркетинга [Электронный ресурс] / Продукты Халяль. Доступ к статье: http://russiahalal. com/ekonomika/osobennosti-khalyalnogo-marketinga.

8. Оразбай А., Сандыбаев А. Надпись «Халал» на товарах в Казахстане заменят на «Адал» [Электронный ресурс] / Zakon.kz. Доступ к статье: www.zakon.kz/4690353-nadpis-khalal-na-tovarakh-v-kazakhstane.html.

9. Работать только с проверенными органами по сертификации Халяль [Электронный ресурс] / Продукты Халяль. Доступ к статье: http://russiahalal.com/mneniya/rabotat-tolko-s-proverennymi-organami-po-sertifikatsii-khalyal.

10. Рынок халяль: международный опыт и малазийская практика [Электронный есурc] / MuslimEco.Ru. Доступ к статье: http://muslimeco.ru/opubl/351/.

11. Титова Д. Развитие индустрии «Халяль» в Росси [Электронный ресурс] / rosfood.info. Доступ к статье: http://rosfood. info/upload/iblock/8fb/44-45.PDF.

12. Тюекпаева 3.Б., Шакиров А.Т. «Халал» - гарантия качества и безопасности // «Байтурсыновские чтения - 2014». 2014. - C. 67-69.

13. «Халяль» - на «адал», и видеокамеры на производство! [Электронный ресурс] / Исламское обозрение. Доступ к статье: http://islamreview.ru/news/halal-na-adal-i-videokamery-na-proizvodstvo/.

14. В Казахстане надпись «Халал» на товарах заменят на «Адал» [Электронный ресурс] / NUR.KZ. Доступ к статье: http://news.nur.kz/355409.html.

15. Марку Ж. Социальные функции институтов гражданского права (на примере законодательства о защите прав потребителей) // Журнал зарубежного законодательства и сравнительного правоведения / Journal of foreighn legislation and comparative law. -2014 . - 5. - C. $771-773$.

\section{References (transliterated):}

1. Akhmetova D. Rossiya - Organizatsiya Islamskogo Sotrudnichestva: novye perspektivy sotrudnichestva v sfere «Khalyal'» industrii [Elektronnyi resurs] / OS Soveta muftiev Rossii. Dostup k stat'e: www.muslim.ru/articles/114/1269/.

2. Kanafina Zh. Skandal na rynke khalal v Kazakhstane. Kto podlozhil svin'yu? [Elektronnyi resurs] / centrasia.ru. Dostup k stat'e: www.centrasia.ru/news2.php?st=1408137780; www.caravan.kz/article/90400.

3. Karimova Zh., Akimbekova A. Khalal na svobode [Elektronnyi resurs] / VOX POPULI. Dostup k stat'e: www.voxpopuli.kz/ main/2136-khalal-na-svobode.html.

4. Kirikova A.A., Abakumova E.V. Sovremennye tendentsii v sfere zashchity prav potrebitelei: problemy sertifikatsii na rossiiskom potrebitel'skom rynke // Yuridicheskie issledovaniya. - 2015. - № 2. - S.1-11. DOI: 10.7256/2409-7136.2015.2.14097. URL: http://e-notabene.ru/lr/article_14097.html.

5. Orazbai A., Sandybaev A. Nadpis' «Khalal» na tovarakh v Kazakhstane zamenyat na «Adal» [Elektronnyi resurs] / Zakon. kz. Dostup k stat'e: www.zakon.kz/4690353-nadpis-khalal-na-tovarakh-v-kazakhstane.html.

6. Titova D. Razvitie industrii «Khalyal'» v Rossi [Elektronnyi resurs] / rosfood.info. Dostup k stat'e: http://rosfood.info/upload/ iblock/8fb/44-45.PDF.

7. Tyuekpaeva Z.B., Shakirov A.T. «Khalal»-garantiya kachestva i bezopasnosti // «Baitursynovskie chteniya - 2014». - 2014. -S. 67-69.

8. Marku Zh. Sotsial'nye funktsii institutov grazhdanskogo prava (na primere zakonodatel'stva o zashchite prav potrebitelei) // Zhurnal zarubezhnogo zakonodatel'stva i sravnitel'nogo pravovedeniya / Journal of foreighn legislation and comparative law. - 2014. - 5. - C. $771-773$. 